\title{
Utero-Ovarian Inguinal Hernia, A Rare Entity in Pediatrics: A Case Report
}

\author{
M. Ouha*, A. Benhima, B. Zouita, D. Basraoui, H. Jalal
}

Radiology department of the mother-child hospital Mohammed VI University Hospital Center Cadi Ayad University Marrakech, Morocco

DOI: $10.36347 /$ sasjm.2021.v07i04.010

| Received: 16.03.2021 | Accepted: 22.04.2021 | Published: 29.04.2021

*Corresponding author: M. Ouha

\section{Abstract}

Although inguinal hernias containing the ipsilateral ovary and tube are common in young girls, those containing the uterus, ovary, and tube are rare. We report a case in a newborn girl presenting an inguinal swelling. An ultrasound performed revealed a hernial sac containing the uterus, an ovary and probably the ipsilateral tube, which is a rare condition. We suggest that ultrasound should be used in the diagnosis of every inguinal formation especially in young girls.

Keywords: ipsilateral tube, uterus, ovary, inguinal swelling.

Copyright $\odot 2021$ The Author(s): This is an open-access article distributed under the terms of the Creative Commons Attribution 4.0 International License (CC BY-NC 4.0) which permits unrestricted use, distribution, and reproduction in any medium for non-commercial use provided the original author and source are credited.

\section{INTRODUCTION}

Inguinal hernia is a common pathology in infants, especially premature infants. It affects boys more with a sex ratio of 6/1. In girls, the inguinal hernia involves the ovary and the tube in 15 to $20 \%$ of cases. However, the presence of a uterus within the hernial sac is a very rare situation and not frequently described in the literature [1].

We report a case of an infant with an uteroovarian hernia revealed by inguinal swelling.

\section{OBSERVATION}

A female newborn aged 15 days was admitted to the emergency department for a painful swelling of the left inguinal region, this swelling was present since birth, it increases in size during cries and regresses during quiet periods (sleep).

Clinical examination found left inguinal mass, hard, inflammatory, painful and irreducible. An ultrasound was performed, revealing a hernial sac containing the uterus and the two ovaries emerging through a neck measuring $10 \mathrm{~mm}$ across the left inguinal canal. These organs were well vascularized in color Doppler, with conservation of their mobility, which made it possible to reduce the hernia during the ultrasound scanning (fig 1). 


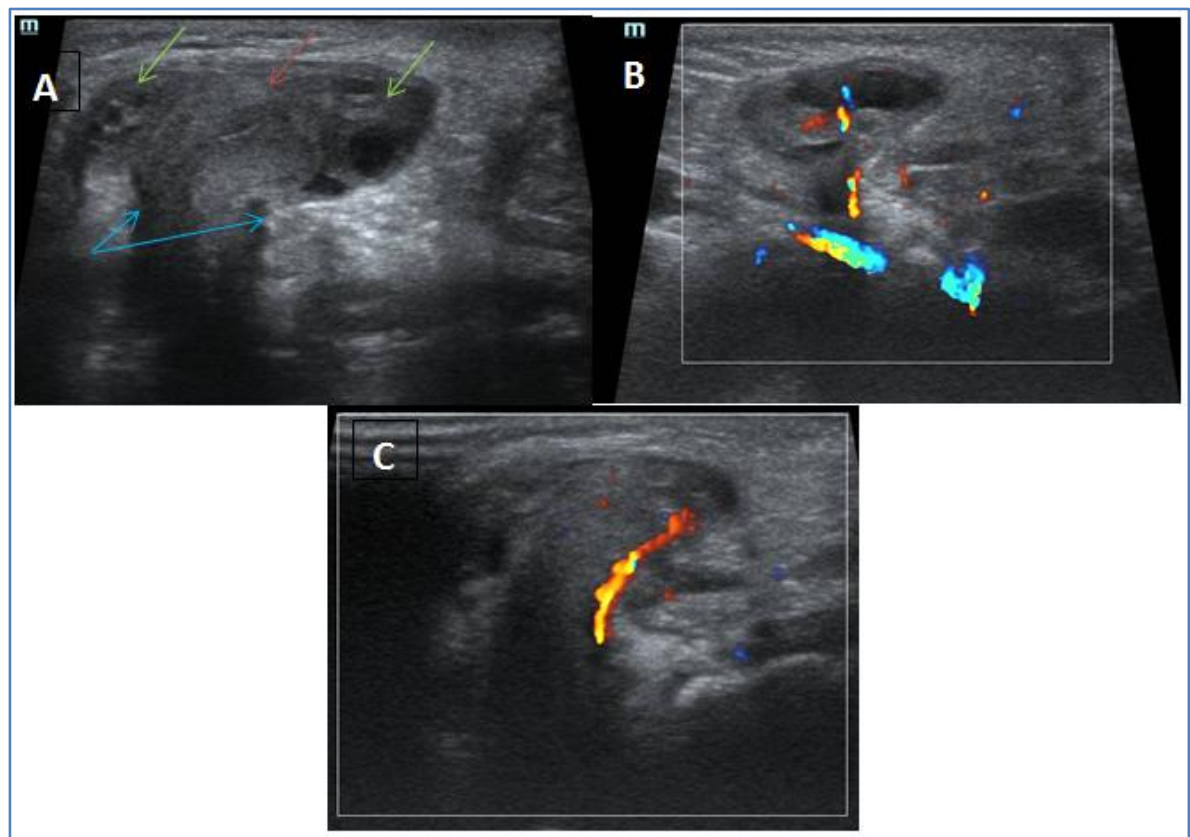

Fig-1: Ultrasound images showing a hernial sac containing the uterus (red arrow) and both ovaries (green arrow) issued through a collar (blue arrows) of approximately $1 \mathrm{~cm}$. These organs retain their vascularization on color Doppler (fig 1B). Reduction of the hernia was obtained during ultrasound examination (fig 1C)

\section{DISCUSSION}

The vaginalis processes develop during the second semester as an evagination of the parietal peritoneum which accompanies the round ligament of the uterus and passes through the inguinal canal to the labia majora, before obliterating around the 8th month of pregnancy. However this process can remain permeable and in this case it is called the Nuck canal $[2]$.

In female infants, the hernial sac usually contains the ovary and sometimes the fallopian tube. However, an inguinal hernia containing the uterus is extremely rare and few cases are published in the literature [3].

The diagnosis of this hernia is clinical without it being possible to determine the contents of the hernial sac, that's why an ultrasound must be systematically performed. It is usually sufficient for a complete preoperative workup. It visualizes the uterus in the inguinal canal with one or both ovaries and their tubes, which are generally mobile. Doppler is also useful to look for signs of adnexal torsion.

In utero-ovarian inguinal hernias the risk of complications (incarceration) is greater than the risk of complications of hernias containing intestines. It has therefore been suggested that any irreducible hernia containing the uterus and / or ovary, even if it is not painful, should be treated as a surgical emergency [4, $5]$.

\section{CONCLUSION}

In front of any inguinal mass in a female infant, an inguinal hernia should be suspected, especially in premature infants. This diagnosis must be confirmed subsequently by an ultrasound which specifies the contents of the hernial sac and looks for signs of complications.

\section{REFERENCES}

1. George EK, Oudesluys-Murphy AM, Madern GC, Cleyndert P, Blomjous JG. Inguinal hernias containing the uterus, fallopian tube, and ovary in premature female infants. J Pediatr. 2000; 136:696-8.

2. Cascini V, Lisi G, Di Renzo D, Pappalepore N, and Lelli Chiesa P, "Irreducible indirect inguinal hernia containing uterus and bilateral adnexa in a premature female infant: report of an exceptional case and review of the literature," Journal of Pediatric Surgery. E17-E19, 2013.

3. Okada T, Sasaki S, Honda S, Miyagi H, Minato M, Todo S. Irreducible indirect inguinal hernia containing uterus, ovaries, and Fallopian tubes. Hernia. 2012;16:471-3

4. Cascini V, Lisi G, Di Renzo D, Pappalepore N, Lelli Chiesa P. Irreducible indirect inguinal hernia containing uterus and bilateral adnexa in a premature female infant: report of an exceptional case and review of the literature. J Pediatr Surg. 2013; 48:17-9.

5. Ming YC, Luo CC, Chao HC, Chu SM. Inguinal hernia containing uterus and uterine adnexa in female infants: report of two cases. Pediatr Neonatol. 2011; 52:103-5. 